\title{
O processo de ressocialização de ex-detentas participantes de projetos sociais no Brasil
}

\author{
The process of resocialization of former indetainers participating in social projects in Brazil \\ El proceso de resocialización de ex reclusas que participan en proyectos sociales en Brasil
}

\author{
Maria Luisa Iannuzzi Carneiro \\ ORCID: https://orcid.org/0000-0002-2325-7621 \\ Centro Universitário FAMETRO, Brasil \\ E-mail: iannuzzimaria@outlook.com \\ Vitoria Millena Marques dos Santos \\ ORCID: https://orcid.org/0000-0001-9090-1790 \\ Centro Universitário FAMETRO, Brasil \\ E-mail.vimillenasantos@gmail.com \\ Júlio César Pinto de Souza \\ ORCID: https://orcid.org/0000-0003-3622-1393 \\ Centro Universitário FAMETRO, Brasil \\ E-mail: cmte01@yahoo.com.br
}

\begin{abstract}
Resumo
A partir de uma leitura inicial, pode-se inferir que ex-detentas têm melhores oportunidades a partir de Projetos Sociais de Ressocialização, podendo trazer ainda mais benefícios quando se tem a atuação de um psicólogo, tanto para a para revitalização da humanização dessas mulheres, como no levantamento de informações pertinentes, para que essas exdetentas tenham melhores condições de vida fora das penitenciarias, através de psicoterapias e na ajuda do desenvolvimento de palestras pertinentes ao público-alvo. Por este fato, o presente estudo tem por objetivo discutir o trabalho de ressocialização com mulheres egressas de penitenciárias realizados através de projetos sociais brasileiros. A pesquisa tem um procedimento bibliográfico e abordagem qualitativa. O levantamento dos dados foi realizado nas plataformas Pepsic, Scielo, Sites Institucionais, além dos Sites do Supremo Tribunal Federal e do Conselho Regional de Psicologia de São Paulo; Resoluções extraídas do Tribunal de Justiça do Amazonas, além de materiais colhidos na biblioteca do Centro Universitário FAMETRO. Por este fato, o presente estudo tem por objetivo levantar reflexões sobre o que é a ressocialização, além de discorrer sobre o mercado de trabalho e o preconceito social sofrido por essas mulheres enquanto ex-detentas, mostrando a importância de projetos sociais brasileiros de ressocialização, o papel do psicólogo e sua importância nesses projetos sociais. Por este fato, os resultados levantados foram que pelo fato dessas mulheres receberem o apoio, a assistência que necessitam, além de receberem oportunidades que talvez não pudessem encontrar de outra maneira, como os cursos disponibilizados, estes projetos ajudam, de certa forma, estas a conseguirem voltar a ter uma vida digna. Portanto, se faz a importância da discussão de outros temas, como a importância dos projetos sociais com mulheres ainda em cárcere e o levantamento estatístico dos benefícios que os Projetos Sociais podem trazer. Palavras-chave: Ex-Detentas; Ressocialização; Projetos sociais.
\end{abstract}

\begin{abstract}
From an initial reading, it can be inferred that former inmates have better opportunities from Social Resocialization Projects, which can bring even more benefits when there is the work of a psychologist, both for the revitalization of the humanization of these women, as in the gathering of relevant information, so that they have better living conditions when they leave the penitentiaries. The research has a bibliographic procedure and a qualitative approach. The data survey was done from the platforms Pepsic, Scielo, Institutional Sites, besides the Sites of the Federal Supreme Court and the Regional Council of Psychology of São Paulo; Resolutions extracted from the Court of Justice of Amazonas, besides materials collected from the library of the University Center FAMETRO. For this fact, the objective of this study is to raise reflections on what resocialization is, besides discussing the labor market and the social prejudice suffered by these women, showing the importance of Brazilian social projects of resocialization, the role of the psychologist and his importance in these projects. For this fact, the results raised were that because these women receive the support and assistance they need, in addition to receiving opportunities that they might not have found otherwise, such as the courses made available, these projects help, in a certain way, these women to get back to a dignified life. Therefore, within this context, other issues to be addressed are the importance of these projects with women still in prison and the statistical survey of the benefits that these projects can bring.
\end{abstract}

Keywords: Ex-Inmates; Resocialization; Social projects. 


\begin{abstract}
Resumen
De una lectura inicial, se puede inferir que las ex reclusas tienen mejores oportunidades a partir de los Proyectos de Resocialización Social, que pueden traer aún más beneficios cuando existe la acción de un psicólogo, tanto para la revitalización de la humanización de estas mujeres, como en la recolección de información relevante, para que tengan mejores condiciones de vida cuando salgan de los centros penitenciarios. La investigación tiene un procedimiento bibliográfico y un enfoque cualitativo. El levantamiento de datos fue realizado a partir de las plataformas Pepsic, Scielo, Sitios Institucionales, además de los Sitios del Supremo Tribunal Federal y del Consejo Regional de Psicología de São Paulo; Resoluciones extraídas del Tribunal de Justicia de la Amazonia, además de materiales recogidos en la biblioteca del Centro Universitario FAMETRO. Por este hecho, el objetivo de este estudio es plantear reflexiones sobre lo que es la resocialización, además de discutir el mercado laboral y el prejuicio social que sufren estas mujeres, mostrando la importancia de los proyectos sociales brasileños de resocialización, el papel del psicólogo y su importancia en estos proyectos. Por este hecho, los resultados planteados fueron que debido a que estas mujeres reciben el apoyo, la asistencia que necesitan, además de recibir oportunidades que quizás no podrían encontrar de otra manera, como los cursos disponibles, estos proyectos ayudan, de alguna manera, a que estas mujeres puedan volver a tener una vida digna. Por lo tanto, dentro de este contexto, otras cuestiones que deben abordarse son la importancia de estos proyectos para las mujeres que aún están en prisión y el estudio estadístico de los beneficios que pueden aportar estos proyectos.
\end{abstract}

Palabras clave: Exdetenciones; Resocialización; Proyectos sociales.

\title{
1. Introdução
}

A ressocialização de ex-presidiárias é uma proposta que vem sendo utilizada em projetos governamentais como prática para ajudar a reestabelecer o vínculo de mulheres, que passaram pelo cárcere. A proposta vem sendo implementada pelo alto índice de mulheres encarceradas no Brasil onde, segundo Petraglia (2019), tem "a quarta maior população de detentas no mundo. São mais de 42 mil em situação de encarceramento.” (p. 1).

Segundo Stephanou, Müller e Carvalho (2003) “os projetos sociais são ações estruturadas e intencionais, de um grupo ou organização social, que partem da reflexão e do diagnóstico sobre uma determinada problemática e buscam contribuir, em alguma medida, para “um outro mundo possível.” (p. 11).

Concluísse que pessoas egressas do sistema prisional são todas as que deixam o estabelecimento carcerário, a contar do prazo de um ano de sua saída ou que se encontram, por progressão de pena, em regime aberto (Lanfredi, Pimenta, Horta, Daufemback, Souza \& Zampier, 2020). Sabe-se que as penitenciárias, presídios, cadeias ou prisões deixam inúmeras marcas em quem passa por eles, podendo desencadear consideráveis prejuízos às condenadas, refletidos no âmbito físico, psicológico, emocional e social.

Portanto, os projetos sociais vêm para amparar essas detentas, buscando trazer aconselhamentos, palestras, cursos profissionalizantes, programas assistenciais governamentais e das práticas do empreendedorismo, para estimular essas mulheres a não voltarem para a vida do crime. Essas mulheres concluem o projeto com melhores oportunidades de reinserção na sociedade, principalmente em questões de empregabilidade que é um dos principais fatores para que elas se reestabeleçam como cidadãs e tenham o direito de reconstruir sua vida com dignidade.

Entretanto, apesar do profícuo trabalho de profissionalização desenvolvido nos projetos, existem outros obstáculos a serem enfrentados no processo de ressocialização, sendo um dos principais o preconceito da sociedade com relação a essas mulheres. A estigmatização da sociedade em relação a elas leva muitas a se isolarem, dificultando assim sua reinserção social e no mercado de trabalho, onde se deparam com o que a sociedade impõe, sobre a pessoa que já passou pelo cárcere, e em relação ao trabalho, além dos empregadores negarem trabalho por preconceito, oferecem salários muito abaixo do que se deve ser aplicado. Todos esses fatores podem levar muitos a voltarem para a vida do crime, o que pode ocasionar problemas de autoestima, abandono e desconforto social.

Tendo conhecimento de tais óbices a serem enfrentadas por essas mulheres, surge a figura do psicólogo no contexto de reinclusão social. Este profissional terá uma participação fundamental na vida destas mulheres, que ao saírem, estarão vulneráveis frente a sociedade, visto que tem o hábito de estigmatizar a imagem das pessoas que passaram pelo sistema carcerário, levando 
em consideração que, apesar de terem cumprido pena, independente do que as levaram à prisão, sofrem mais uma vez o preconceito, sendo tratadas como uma ameaça à população.

Os pesquisadores nortearam seus trabalhos com o objetivo primário da pesquisa de discutir o trabalho de ressocialização com mulheres egressas de penitenciárias realizados por projetos sociais brasileiros. Nessa investigação apresenta-se uma reflexão sobre o que é ressocialização, fazendo o levantamento das dificuldades enfrentadas pelas mulheres para se reestabelecerem na sociedade, como o funcionamento do mercado de trabalho e o preconceito social sofrido por essas mulheres. Outra questão explorada na pesquisa foi discutir sobre importância do trabalho de projetos sociais de ressocialização de ex-detentas, bem como foi discutido sobre o papel do psicólogo e sua importância nos projetos sociais. Para além deste estudo, ainda existem outras temáticas a serem abordadas, como por exemplo a importância dos projetos sociais com mulheres ainda em cárcere e o levantamento estatístico dos benefícios que os Projetos Sociais podem trazer.

Com relação às contribuições deste trabalho à sociedade entende-se que os resultados da pesquisa contribuirão para desmistificação de que egressas do sistema prisional não tem espaço para voltar a fazer parte da sociedade, bem como de que não podem reestabelecer sua cidadania, visto que a pesquisa mostra que com a ajuda da sociedade, existe certa facilidade para que essas mulheres consigam sair da vida do crime.

Esta pesquisa oferece uma contribuição para a academia e para a comunidade científica, apresentando a importância dos projetos sociais de ressocialização, bem como a importância de ter um psicólogo nesses projetos. Ao apresentar a relevância no trabalho do psicólogo com as egressas durante o seu processo de ressocialização, estimula-se a comunidade acadêmica a realizar novas pesquisas sobre a importância da psicologia no processo de ressocialização de egressas no sistema prisional participantes de projetos sociais no Brasil.

\section{Percurso Metodológico}

Esta pesquisa foi realizada a partir de uma Pesquisa Bibliográfica de caráter Qualitativo. De acordo com Gerhardt e Silveira (2009) a Pesquisa Bibliográfica "é feita a partir do levantamento de referências teóricas já analisadas, e publicadas por meios escritos e eletrônicos, como livros, artigos científicos, páginas de web sites.” (p. 37). A escolha da Abordagem Qualitativa se deu pelo fato de ser uma abordagem subjetiva, onde, segundo Godoy (1995), "ocupa um reconhecido lugar entre as várias possibilidades de se estudar os fenômenos que envolvem os seres humanos e suas intrincadas relações sociais, estabelecidas em diversos ambientes." (p. 21).

Para a construção desta pesquisa foram utilizados como instrumentos: livros, periódicos, artigos, monografias no âmbito científico, resoluções, leis e noticiários, que permitirão a coleta de informações a partir de materiais já publicados, uma vez que já se tem conhecimento de sua existência. Publicados nas plataformas Pepsic, Scielo, Sites, Portais Institucionais, além dos Sites do Supremo Tribunal Federal e do Conselho Regional de Psicologia de São Paulo; Resoluções extraídas do Tribunal de Justiça do Amazonas, além de materiais colhidos na biblioteca do Centro Universitário FAMETRO. A fim de selecionar os trabalhos que tivessem relação com o tema, escolheu-se os descritores: Ressocialização; Papel do Psicólogo; Projetos Sociais; Ex-detentas.

A análise das publicações fora conduzida, primeiramente, a partir da seleção de trabalhos com títulos ligados ao assunto, sendo descartados as publicações repetidas e incompletas. Em seguida realizou-se uma leitura dos resumos e sinopses das obras, onde foram desconsideradas aquelas publicações desalinhadas à sugestão desta pesquisa. Por fim, os trabalhos escolhidos passaram por uma leitura centralizada e interpretativa, com a finalidade de se estabelecer uma linha de colocações e pensamentos dos autores quanto à temática deste artigo.

Desta forma, a partir da análise das fontes, foram selecionados 11 (onze) artigos científicos, 1 (um) trabalho acadêmico, 4 (quatro) livros, 2 (duas) leis, 2 (duas) resoluções, e 15 (quinze) sites institucionais, sendo 34 em português e 1 em espanhol. Os Sites Institucionais são todos os endereços de empresas, instituições ou organizações, disponibilizados na internet. 
O conteúdo de um site institucional é composto por toda a informação que a empresa irá apresentar nesse seu ambiente, como: a divulgação detalhada do que a empresa faz; os produtos e serviços oferecem aos seus clientes; uma explicação sobre sua área de atuação; dados para contato; mapa de onde a empresa está localizada; vídeos comerciais ou sobre assuntos correlatos à área de atuação; entre outros. (Nassar \& Vieira, 2017, p. 123)

Visto a necessidade de fundamentar o trabalho nas Leis, decretos e Resoluções que tratam do assunto, sendo que muitas delas são mais antigas, as publicações selecionadas para a discussão do assunto foram produzidas no período de 1984 a 2021.

\section{Resultados e Discussão}

\subsection{Ressocialização de Egressos Prisionais}

Segundo o Art. 25, do capítulo 8, instituído na Lei no 7.210, de 11 de julho de 1984, mais conhecida como Lei de Execução Penal (LEP), considera-se egresso o liberado definitivo, pelo prazo de um ano a contar da saída do estabelecimento e o liberado condicional, durante o período de prova (Brasil, 1984).

Portanto, a ressocialização visa desenvolver habilidades sociais para que as detentas tenham condições de voltarem ao meio social e possam buscar se reestabelecer no mercado de trabalho, recriando suas vidas e tendo, assim, uma vida digna. Essas habilidades sociais adquiridas nos projetos buscam preparar as mulheres para voltarem para a sociedade como cidadãs e não reincidirem na vida do crime. Além disso, o ambiente carcerário, desencadeia inúmeros prejuízos aos condenados, prejuízos esses refletidos no âmbito físico, psicológico, emocional e social. Sendo assim, a ressocialização destes indivíduos tem o propósito de oferecer dignidade, tratamento humanizado, conservando a honra e a autoestima (CFP, 2009).

Um dos principais fatores na ressocialização é estimular as pessoas a trabalharem, com isso, são criados projetos sociais que visam ajudar e amparar as ex-detentas nesse contexto.

Entretanto é comum surgirem dificuldades em conseguir se inserir no mercado de trabalho e até mesmo de serem vistas como cidadãs pelo alto preconceito existente na sociedade.

\subsection{Os Desafios da Ressocialização das Ex-Presidiárias}

\subsubsection{O Mercado de Trabalho para as Ex-Presidiárias}

Ribeiro (2017) fala que "o trabalho aliado à capacitação profissional é um instrumento importante na reeducação" (p. 370), ou seja, o trabalho está totalmente ligado a ressocialização de ex-presidiárias, pois este fator desencadeia a vontade de voltar a ter uma vida normal, ajuda a fortalecer a autoestima visto que ela consegue, a partir disto, se sustentar e sustentar sua família, além de ser o principal fator de não reincidência na vida do crime. Logo, por este fato, o Estado assume o papel de assegurar para todas as pessoas que desejam trabalhar, condições e oportunidades mínimas de sobrevivência ao saírem do encarceramento, ainda que provisoriamente (Dias \& Oliveira, 2014).

Sobre o trabalho das detentas, Souza, Costa e Lopes (2019) ainda falam que "relações de gênero também permeiam o processo de ressocialização pelo trabalho, produzindo outras formas de estigmatização, pois as atividades comumente destinadas às presas são de costura, limpeza e produção de artesanato”. (p. 366). Por este fato, existe a importância e necessidade da criação de projetos que visem a profissionalização de egressas do sistema prisional, para que as mesmas desenvolvam habilidades para a melhor reinserção no mercado de trabalho, para que assim não sofram com a reincidência criminal, pela falta de oportunidade que as cercam, além de todo preconceito estipulado pela sociedade, pelo fato de que, além do sistema prisional, a sociedade ainda encontra-se muito machista, causando dificuldade para estas mulheres.

Ao sair da prisão, essas ex-detentas não encontram condições que favoreçam sua ingressão no mercado de trabalho pois estas levam consigo um estigma social negativo de ser uma ex-detenta. Este preconceito é uma maneira de punição invisível em 
que a ex-detenta levará com ela durante toda a sua vida. Existem restrições legais que impendem uma ex-detenta de conseguir um emprego.

Todavia, é possível também, por meio do “ato de trabalhar", dentro de um meio ambiente de trabalho saudável, construir uma vida melhor do que aquela dentro da prisão, o que significa que o trabalho deixa de ser uma mercadoria, ganhando a condição de valor social necessária para o resgate da dignidade do ex-apenado (Dias \& Oliveira, 2014, p. 150)

Por este fato, sobre capacitação profissional, Cambria (2018), ainda fala que é importante destacar "que os cursos profissionalizantes disponibilizados para as ex-detentas, estejam sempre aprimorados, e que possibilitem que essas mulheres deem continuidade ao curso escolhido ao longo do tempo, após saírem do encarceramento.” (p. 37).

\subsubsection{O Preconceito Social}

O preconceito social, segundo Novo (2019), "pode se manifestar por reações de intolerância e de dificuldade de convivência com indivíduos que não pertencem ao mesmo grupo social” (p. 3). Neste caso, em específico, por se tratar de egressas, existe essa intolerância da sociedade em relação a elas quanto ao que diz respeito a convivência, onde essa sociedade pode vir a não acreditar na mudança de pessoas que passam pelo sistema prisional.

Segundo Boeira et al. (2020) “os impactos negativos do estigma contra pessoas egressas do sistema prisional e suas famílias podem afetar tanto o nível individual quanto comunitário, dificultando a reinserção social desse público e fragilizando vínculos sociais". (p. 6).

Após a liberdade, as ex-detentas encontram um novo desafio, conseguir se reestabelecer na sociedade, e o primeiro passo é conseguir se reinserir no mercado de trabalho. Helpes (2020, p. 103) comenta sobre essa dificuldade:

As péssimas condições de trabalho vivenciadas antes e durante o período em que cumpriam pena privativa de liberdade não terminam quando a detenta recebe seu alvará de soltura. Agora ela tem um novo desafio: retomar sua vida com o estigma de ser uma mulher ex-presidiária. Para uma mulher que já acumula diversas desvantagens ao colocar-se no mercado de trabalho, tais como, baixa escolaridade, falta de apoio financeiro de membros da família, única responsável pelos filhos etc., a passagem pela prisão pode apresentar-se enquanto elemento definitivo na sua permanência nas fileiras mais baixas do precariado.

Por este fato, muitas detentas não buscam se especializar em quaisquer que sejam as profissões que poderiam seguir fora da cadeia, pois, após saírem do presidio, ficam à mercê de um mercado de trabalho exigente e preconceituoso. Onde segundo Leandro, Córdova, Castro e Kern (2018), mesmo com seus “direitos assegurados pela constituição e de todo o movimento para a redução das ações discriminatórias, muitas mulheres acabam se deparando com desigualdades, preconceitos e discriminações sociais" (p. 125).

Quanto a contextualização biográfica do público encarcerado, trata-se de pessoas cuja experiência do aprisionamento acumula consequências que agravam o processo de estigmatização e exclusão social. Se para os cidadãos, moradores de periferias, com baixa escolaridade e baixa renda, o acesso a políticas públicas e a oportunidades de ascensão social já são insuficientes e desiguais, em relação ao egresso do sistema prisional, esse contexto de vulnerabilidades é complementado e agravado pelo rótulo de condenado, pela perda da subjetividade, pelo distanciamento dos vínculos familiares e comunitários, pelo atestado de antecedentes criminais e pelo preconceito social que praticamente transforma uma pena temporária de privação de liberdade em pena de perpétua (Leandro, Córdova, Castro \& Kern, 2018, p. 127).

No geral, é perceptível que as mulheres que carregam consigo o peso de serem ex-condenadas, ou seja, mulheres que passaram pelo sistema carcerário, muitas vezes somatizam outros estigmas sociais, podendo ser ligadas a extrema pobreza, falta de instrução, cultura territorial, e principalmente o ambiente em que vivem, o que leva a aumentar preconceito e a discriminação 
social, tornando-os mais cruéis (Leandro, Córdova, Castro \& Kern, 2018). O que pode se tornar ainda mais dificultoso, caso essa mulher não possua qualificações profissionais, sofrendo com a incerteza do mercado de trabalho (Oliveira \& Nunes, 2018).

Uma outra dificuldade encontrada e talvez o fator de maior sofrimento para as presidiárias, é a forma como são tratadas, pois, mais do que os homens, são moral e socialmente condenadas, pela sociedade e principalmente pela família (Ribeiro, 2017). O que pode gerar problemas de autoestima e abandono e desconforto social.

\subsection{Projetos Sociais: Uma Possibilidade de Ressocialização das Ex-Presidiárias}

Segundo Stephanou, Müller e Carvalho (2003) os projetos sociais “são ações estruturadas e intencionais, de um grupo ou organização social, que partem da reflexão e do diagnóstico sobre uma determinada problemática e buscam contribuir, em alguma medida, para um outro mundo possível”. (p. 11).

São entendidos como um conjunto de propostas e compromissos de ação voltados para uma finalidade, que têm por objetivo causar impactos em populações alvo, grupos alvo ou beneficiários. Os impactos causados por esses projetos visam satisfazer necessidades básicas, oferecer experiências, mudar as condições de vida, os comportamentos, valores ou atitudes que sustentam tal público-alvo, e para que isso aconteça, deve existir certa mobilização tanto por parte da pessoa responsável pela execução desse projeto quanto do destinatário dele. (Nogueira, 1998).

Existem diversos projetos sociais voltados para a ressocialização de ex-detentos. A partir de uma pesquisa foram levantados alguns projetos em âmbito nacional, porém, que abordam esse assunto e apresentam práticas eficazes com o intuito de contribuir para a ressocialização de ex-detentas, ou seja, projetos que trabalhem com mulheres, em específico. Esses projetos ajudam essas mulheres a saírem da vulnerabilidade social, buscando empregabilidade, autonomia, melhores condições de vida e autoestima. A seguir, trataremos sobre alguns desses projetos.

\subsubsection{Projeto Reeducar}

O Projeto Reeducar, é um subgrupo do Grupo de Monitoramento Carcerário, instituído pelo Tribunal de Justiça do Estado do Amazonas, e "tem como proposta o desenvolvimento de ações de responsabilidade social, fora do ambiente carcerário, para promover apoio sociopsicopedagógico" aos beneficiados com a Liberdade Provisória, não existe uma quantidade certa de regressos participantes, mas varia de 100 a 180 a cada 15 dias, mensalmente (TJAM, 2019).

Neste projeto é realizado aconselhamentos, palestras, cursos profissionalizantes, programas assistenciais governamentais e das práticas do empreendedorismo, com intuito também de amenizar o problema da superpopulação dos presídios. O Art. $1^{\circ}$, da Resolução n 14, de 27 de maio de 2010, institui “o Projeto Reeducar [...], com o objetivo de promover ações de reinserção social de liberados provisórios do sistema carcerário, com o apoio da Defensoria Pública do Estado do Amazonas.”. (Amazonas, 2010, p. 1)

O projeto trabalha de forma ativa para conseguir, de modo benéfico, a ressocialização das pessoas que passam por ele. Este projeto social “[...] compõe-se de um conjunto de ações educativas, de capacitação profissional e de reinserção no mercado de trabalho" (TJAM, 2010, p. 1)

De acordo com o site institucional do Tribunal de Justiça do Estado do Amazonas, o projeto Reeducar tem por intenção promover amparo social, abrangendo família, trabalho, educação, cultura, dentre outros, oferecendo alternativas que venham resgatar os valores pertinentes à cidadania, criando um espaço para discussões e reflexões sobre os efeitos causados por eventual reincidência criminal, valorando sua liberdade pois este, tendo experimentado os dramas da realidade do presídio, imprime em sua vida, novos ideais e valores fundamentais em uma prática laborativa responsável. 
Os projetos sociais nascem do desejo de mudar uma realidade. Os projetos são pontes entre o desejo e a realidade. São ações estruturadas e intencionais, de um grupo ou organização social, que partem da reflexão e do diagnóstico sobre uma determinada problemática e buscam contribuir, em alguma medida, para um outro mundo possível (Stephanou, Müller \& Carvalho, 2003, p. 11).

O Projeto "Reeducar” possui parcerias com diversas Instituições, entidades e autarquias. Essas parceiras disponibilizam cursos profissionalizantes, palestras, orientação e aconselhamento para os egressos que participam do Projeto Reeducar, além da ajuda de Juízes de Direito, Promotores de Justiça, Defensores Públicos, Assistentes Sociais e Psicólogos (TJAM, 2019).

Com o objetivo de promover apoio socio psicopedagógico aos beneficiados com a Liberdade Provisória, o projeto Reeducar traz ações que desenvolvam a responsabilidade social. Entende-se, portanto que o projeto trabalha para que estes egressos possam alcançar a ressocialização através de ações como aconselhamentos, palestras, cursos profissionalizantes, programas assistenciais governamentais e das práticas do empreendedorismo.

\subsubsection{Programa Trabalhando a Liberdade}

O programa "Trabalhando a liberdade" foi criado em 2019, pela Secretaria de Estado de Administração Penitenciaria SEAP, e tem como objetivo garantir o trabalho através do uso da mão de obra dos beneficiários do projeto, em reformas, manutenções e entre outros trabalhos, sendo eles dentro ou fora das prisões. Para participar deste projeto, as detentas e exdetentas, passam por uma análise comportamental, para verificação do perfil psicológico, para que se assegurem de como esta mulher possa vir a se portar diante dos trabalhos e do meio social que será inserida. Segundo Nascimento (2020), “mais de 75\% das detentas da Penitenciária Feminina de Manaus” (p. 1), fazem parte do programa.

De acordo com Nascimento (2020), o projeto disponibiliza, atividades como "serviços de limpeza e conservação, costura, lavanderia, cuidados com a horta, estufas, até manutenção de viveiro de minhocas para transformação de adubo e canteiros da unidade prisional" (p. 1), onde segundo Dias e Oliveira (2014), essas atividades têm como objetivo "promover a cidadania e consequentemente diminuir a reincidência de crimes". (p.161). As atividades realizadas têm como objetivo a qualificação do trabalho, a educação através de cursos e a socialização, visando o desenvolvimento pessoal desses indivíduos, pois estas atividades são fundamentais no que diz respeito ao direito a dignidade da pessoa humana (Santos, Barbosa, Lima \& Cassundé, 2018).

Como já foi abordado no tópico "O Preconceito Social”, essas mulheres passam por diversas dificuldades ao saírem da prisão, e o problema com a autoestima é uma delas, onde podem recorrer pensamentos de que não conseguirão viver suas vidas normalmente, logo, podendo voltar a praticar atos ilícitos. Por este fato, o Projeto visa disponibilizar palestras com diversos temas de conhecimento geral e programações com destaque à valorização da mulher, resgate da autoestima e empoderamento feminino, como forma de recuperar a autonomia da regressa e aumentar a vontade de querer sair da vida do crime (Nascimento, 2020)

O programa Trabalhando a Liberdade tem por objetivo conter as transgressões das ex-apenadas a vida do crime, no que diz respeito às taxas de reincidência ao sistema carcerário, visando diminuir estes números, além de também ter o intuito de reprimir os ciclos existentes sobre a criminalidade, através de suas atividades que envolvem capacitação, educação e socialização. O programa atua de forma ininterrupta nos dias de hoje de maneira contributiva não só para o seu público-alvo, mas também para a segurança e bem-estar da sociedade.

Logo, por tudo que foi citado deste projeto, sua importância está no fato de se fazerem os trabalhos desde o momento que a pessoa está apenada até depois que a mesma sai da prisão, pelo fato de já se ter o preparo para quando está se tornar reeducanda do projeto, tornando o trabalho mais eficaz no que se diz respeito a reincidência do crime, pois este mostra a eficácia 
do trabalho, da educação, bem como a importância de se portar bem diante a sociedade, visando, então, uma ressocialização sadia das pessoas que são beneficiadas por ele.

\subsubsection{Projeto Mulheres Livres}

O projeto Mulheres Livres, instituído pelo Departamento Penitenciário Nacional - DEPEN, órgão ligado ao Ministério da Justiça e Segurança Pública, criado em janeiro de 2018, "surge com o objetivo de desencarcerar mulheres privadas de liberdade que estão gestantes ou são mães de crianças na primeira infância" (Lacerda, 2018, p. 1). Este projeto busca cumprir o especificado na Constituição Federal "Todos são iguais perante a lei, sem distinção de qualquer natureza [...] I - homens e mulheres são iguais em direitos e obrigações, nos termos desta Constituição" (Brasil, 1988, p.8). O foco é proteger não somente o direito da mãe de cuidar da criança, mas o direito da criança de ser acolhida pela mãe na primeira infância.

Importante ainda destacar dados sobre o perfil dessas mulheres: 55\% se concentram na faixa etária de 18 a 29 anos; $63 \%$ são negras ou pardas; e $82 \%$ não possuem a educação básica completa. Dentro do sistema prisional, $27 \%$ das mulheres participam de atividades educacionais, que contemplam alfabetização, ensino regular e universitário, qualificação profissional e atividades complementares, como leitura. Já as atividades laborais contam com $26 \%$ das apenadas. É mais que o dobro da participação masculina nas mesmas atividades. Dois terços das mulheres privadas de liberdade têm filhos e mais de 500 crianças estão presas juntos com as mães (Ministério da Justiça e Segurança Pública, 2019, p. 2-3).

Segundo Lacerda (2018), “o Projeto Mulheres Livres não se encerra na fase de soltura de mães detentas. A proposta é oferecer assistência jurídica e treinamento profissional para que essas mulheres se tornem economicamente independentes" (p. 1). Pode-se observar no site de notícias do Ministério de Justiça e Segurança Pública (2017), que este projeto ainda conta "com o apoio do Sistema Único de Assistência Social, rede formada por CRAS e CREAS, além de centrais de alternativas penais e serviços de referência aos egressos, será garantido a essas mulheres abrigo, documentação e alguns benefícios relativos à assistência social" (p. 3).

O programa Mulheres Livres se divide em quatro fases: a primeira fase consiste numa Coleta de Dados, onde precisa saber quem são essas mulheres que irão participar do projeto, então se faz um levantamento das informações dessas mulheres; a segunda compete às Defensorias Públicas avaliar todos os casos e encaminhá-los para julgamento da justiça; a terceira fase consiste no julgamento dos processos no judiciário; e a quarta fase se trata da Proteção Social onde essas mulheres passam por acolhimento social.

É nesta quarta e última fase do programa, que é inserida a ressocialização de ex-presidiárias, onde essas mulheres, ao serem beneficiadas com a liberdade, recebem capacitação para que cheguem ao mercado de trabalho. Podendo ainda receber abrigo e acessar cursos de conclusão dos estudos, além de cursos profissionalizantes, para que dessa forma, tenham um retorno à sociedade de forma menos agressiva.

O juiz-corregedor Rodrigo Tavares Martins, do Núcleo V da CGJ, destaca a importância do programa Mulheres Livres, o qual tem como objetivos garantir a reinserção qualificada da mulher na sociedade, a integração da política pública de ressocialização, a recolocação das mulheres presas no mercado de trabalho e o acesso à educação para elevação da escolaridade e da profissionalização, além do acesso a serviços de cuidados pessoais e acolhimento das dependentes químicas (Medeiros, 2021, p. 1).

Portanto, este programa ajuda tanto mulheres que ainda estão em cárcere, quanto mulheres que foram soltas, que são mães e possuem o direito de garantir qualidade de vida às crianças que estão gerando ou que estão na primeira infância, tendo em vista um acolhimento que vai além da mãe, para que a criança tenha o seu direito garantido, segundo o Art. 227, do Capítulo 7 da Constituição Federal de 1988. 
“Art. 227. É dever da família, da sociedade e do Estado assegurar à criança, ao adolescente e ao jovem, com absoluta prioridade, o direito à vida, à saúde, à alimentação, à educação, ao lazer, à profissionalização, à cultura, à dignidade, ao respeito, à liberdade e à convivência familiar e comunitária, além de colocá-los a salvo de toda forma de negligência, discriminação, exploração, violência, crueldade e opressão.” (Brasil, 1988, p. 132).

Levando em consideração o número alarmante de mães que estão em cárcere, o Projeto Mulheres Livres é importante para devolver a essas mulheres a maternidade de forma mais sadia, e as crianças o direito de viverem com essa dignidade que deve ser garantida a elas segundo a Constituição Federal.

\subsubsection{Projeto Maria Marias}

O projeto Maria Marias, desenvolvido pela Secretaria de Justiça do Estado do Espírito Santo, tem como objetivo ofertar cursos profissionais e oportunidades de trabalho para mulheres. No Manual de Boas Práticas do Sistema Penitenciário Nacional, Peres e Matos, afirmam que:

O projeto também propõe uma articulação com o Sistema "S” e amplia o conceito de ressocialização focado no trabalho, no empreendedorismo e no fortalecimento do vínculo familiar, minimizando os efeitos do encarceramento e resgatando o potencial da mulher na sua condição de mãe, trabalhadora, empreendedora, educadora, administradora do lar, companheira e cidadã de direitos. (Peres \& Matos, 2009, p. 27)

O projeto Maria Marias realiza esta prática, assim como o “projeto Reeducar”, fortalecendo as relações com o sistema "S". Onde para Niquito, Ely e Ribeiro (2018) esse sistema é "um conjunto de nove organizações que objetivam o treinamento profissional, assistência social, consultoria, pesquisa e assistência técnica para empresas e seus empregados” (p. 200). Dentre as organizações do Sistema S, as que fazem parte do projeto são: SENAI; SESI; SENAC; SEBRAE; SEJUS (Pagotto, 2014).

A Secretaria de Justiça do Espírito Santo ainda disponibiliza palestras que ocorrem semestralmente nas unidades femininas do estado. Geralmente estas palestras trazem temas como família; informações sobre doenças sexualmente transmissíveis, bem como sobre a saúde sexual; maternidade (Peres \& Matos, 2009, p. 27-28).

Este projeto tem o foco propriamente dito em mulheres com o intuito de oferecer cursos profissionalizantes a fim de promover oportunidades de trabalho para as mesmas visto que em suas condições atuais as chances de conseguir sozinha na sociedade seriam menores. Além desses cursos, são oferecidas palestras com temas sociais.

\subsubsection{Projetos de ressocialização da Umanizzare}

A Umanizzare Gestão Prisional (2020) "é a maior empresa de gestão de presídios da América Latina, que tem como objetivo prover sistemas prisionais e socioeducativos de serviços complementares, executados com foco na excelência e com resultados na ressocialização e no desenvolvimento humano". Essa gestão é implementada no Centro de Detenção Provisória Feminino (CDPF) e na Unidade Prisional de Itacoatiara (UPI), ambas no Amazonas.

Dentro dessa Gestão, existem diversos projetos voltados para atender esses objetivos. Um projeto de habilidades sociais é o Projeto Mãos Livres.

O Projeto Mãos Livres tem entre suas metas propiciar aos re-educandos um conjunto de trabalhos manuais de natureza terapêutica, com viés de inserção econômica. Além de terem acesso a noções de técnicas modernas de arte, com foco em sustentabilidade e designer, os re-educandos se familiarizam com planos de negócios, proposta de valores, marketing e análise de mercado (Lira, 2017, p. 1)

A Umanizzare (2020) ainda disponibiliza o Projeto Plantando a Liberdade, que é um projeto inovador, que tem por objetivo levar aos reeducandos acesso as noções básicas de plantio e cuidado com hortas. Criado em 2015, conta com o apoio 
do Instituto de Desenvolvimento Agropecuário e Florestal Sustentável do Amazonas - IDAM, tem caráter terapêutico e profissionalizante e ainda fornece diariamente os produtos extraídos deste trabalho à população carcerária.

Acredita-se que esses projetos de horta podem auxiliar tanto na promoção do bem-estar físico quanto mental, além de desenvolver a educação ambiental e conscientizar sobre a saúde alimentar, promove a autoestima e ensina sobre a dignidade do trabalho, pois estes projetos envolvem seus participantes em serviços comunitários, liderança e tomada de decisão, no que diz respeito ao profissionalismo e habilidades de vida (Filho, 2017, p. 6).

Pode ser o ponto de partida para ensinar e desenvolver a política alimentar, introduzindo os indivíduos nas interconexões da natureza aos sistemas econômicos e à sociedade, representando um modelo histórico e contemporâneo para o desenvolvimento de habilidades profissionais na agricultura, gestão de recursos naturais e ciência (Filho, 2017, p. 6).

Essa gestão ainda conta com o Projeto Lisbela, criado em 2014 no Centro de Detenção Provisória Feminino (CDPF), o projeto Lisbela promove qualificação profissional na área de estética e imagem pessoal. Consiste em um salão de beleza, implantado na unidade prisional para profissionalizar as detentas e ajudar na recuperação da autoestima.

Para entrar nesses projetos, segundo a Umanizzare (2020), a reeducanda precisa passar por uma seleção, feita pelo serviço social, onde serão feitos levantamentos das detentas que realmente querem participar do projeto e estejam aptas para isso, além de passarem por uma entrevista. A partir disso, serão repassadas as informações dessas reeducandas para lojas colaborativas, assegurando a inclusão econômica dessas mulheres.

Ao discorrer sobre estes projetos, pôde observar-se o quão eficiente e importante é a empresa de gestão prisional Umanizzare pois esta disponibiliza não somente um, mas sim vários projetos que contribuem para a ressocialização dessas exdetentas na sociedade e no mercado de trabalho. Tornando-se eficaz no que se diz respeito a humanização dessas mulheres que sofrem com esse estigma de serem ex-presidiárias, contribuindo não só em relação ao trabalho, educação e socialização, mas principalmente no que diz respeito a autoestima destas, onde muitas das vezes se é perdida dentro do ambiente carcerário.

\subsection{O Papel do Psicólogo e sua importância nos Projetos Sociais}

A atuação do Psicólogo pode ser identificada na Resolução n ${ }^{\circ}$ 010/05 do Código de Ética do Psicólogo, do Conselho Federal de Psicologia (2005), no que diz respeito aos Princípios Fundamentais do trabalho do psicólogo, que considera que o psicólogo "trabalhará visando promover a saúde e a qualidade de vida das pessoas e das coletividades e contribuirá para a eliminação de quaisquer formas de negligência, discriminação, exploração, violência, crueldade e opressão”. (p. 7).

Outro fator importante para declarar sobre o trabalho do psicólogo no âmbito criminal, seria citar a Lei $\mathrm{n}^{\circ} 7.210$, de 11 de julho de 1984, mais conhecida como Lei de Execução Penal (1984), onde no Art. 1 diz que “a execução penal tem por objetivo efetivar as disposições de sentença ou decisão criminal e proporcionar condições para a harmônica integração social do condenado e do internado" (p. 1), e ainda nesta Lei de Execução Penal (1984), no Art. 7 que "a Comissão Técnica de Classificação deve conter pelo menos um psicólogo atuante” (p. 1). De acordo com Cruces (2010) o psicólogo “elaborará programa individualizador e acompanhará a execução das penas privativa de liberdade e restritiva de direitos, devendo propor à autoridade competente, as progressões dos regimes, bem como as conversões das penas” (p. 142). Ou seja, foi a partir desta lei que foi efetivado o trabalho e a atuação do psicólogo com presidiários e ex-presidiários, bem como legitimou sua importância.

Cambria (2018) fala sobre a "extrema importância de estudar o público minuciosamente, principalmente nos relatos que elas dão sobre os planos que tem para o futuro e, dessa forma, auxiliar no processo de regeneração" (p. 18), pois, conhecendo individualmente cada uma dessas mulheres, faz com que se sintam mais à vontade para falarem sobre seu caso, permitindo um maior conforto dessa mulher para com o psicólogo. 
O psicólogo deve entender quais são as vontades, as habilidades daquela ex-presidiária para ajudar a promover a mudança pessoal. Onde de acordo com o Conselho Federal de Psicologia e Centro de Referência Técnica em Psicologia e Políticas Públicas (2009, p. 24):

A discussão sobre o papel do(a) psicólogo(a) direcionou-se para a compreensão das contradições existentes na realidade do campo. Foi apontado como tarefa do(a) profissional psicólogo(a), o compromisso de melhorar as condições de vida no presídio, bem como transformar a cultura institucional e garantir os direitos das pessoas presas.

Para além deste fato, o psicólogo deverá seguir arduamente um importante requisito que lhes é ordenado pelo Código de Ética do Psicólogo (2005), que no caso lhe diz para "basear o seu trabalho no respeito e na promoção da liberdade, da dignidade, da igualdade e da integridade do ser humano, apoiado nos valores que embasam a Declaração Universal dos Direitos Humanos". (p. 7). Sendo assim, pode-se dizer que o trabalho do psicólogo, neste âmbito, é voltado para a integração social do sujeito de uma forma harmoniosa com diminuição de danos, tendo então como objetivo a colaboração de seu trabalho, com a finalidade de se estabelecer e cumprir o que se diz na Lei de 1984, que visa fazer o levantamento de discussões realizadas a partir atividades e intervenções que destinam-se ao desenvolvimento da educação, do trabalho e de oportunidades aos sujeitos, visando a defesa de seus direitos humanos.

Portanto, o papel do psicólogo ainda é bastante discutido quando falado sobre seu trabalho com ex-detentas e até mesmo dentro dos presídios, porém este deve tratar destas pessoas como cidadãs. E, além do psicólogo aplicar testes e fazer laudos psicológicos, ele tem em si como objetivo, quando adentra no caso de ressocialização, promover melhores condições de vida, a garantia dos direitos humanos, priorizar a autonomia do sujeito e ainda ajudar as mulheres a buscar resultados mais satisfatórios dentro e fora da prisão. Para além disso, o psicólogo tem um papel fundamental na vida das mulheres, que ao saírem, estarão vulneráveis frente a sociedade, onde estas são julgadas mesmo por cometerem pequenos delitos.

Sabe-se ainda que o sistema carcerário pode gerar inúmeros problemas psicológicos, principalmente se a pessoa já possuir uma certa predisposição para isto.

Os distúrbios ou "doenças psicológicas" são, em sua maioria, causados por fatores orgânicos ou funcionais. Há pessoas que nascem com uma predisposição genética para desenvolver algum distúrbio psíquico, já outras desenvolvem de forma funcional, por uma situação vivida, um fator externo que influenciou seu surgimento. As prisões, sendo entidades com tantos problemas como os já citados, e o período de readaptação social logo que o apenado se torna egresso do sistema carcerário são starts suficientes para se tornarem fatos geradores de alguma disfunção psicológica. (Novo, 2019, p.2)

A partir desta discussão, é possível identificar a importância do papel do psicólogo dentro de projetos sociais que visem a ressocialização de ex-presidiárias, pois, para além da importância do trabalho, de cursos profissionalizantes, essas mulheres têm que estar preparadas para o que vão enfrentar com a liberdade, ajudando-as a terem um psicológico mais resistente aos "nãos" que irão receber da sociedade, focalizando principalmente neste aspecto, dando suporte e auxiliando sobre as dificuldades que irão surgir em suas vidas, visando a não regressão a criminalidade e para que essa ressocialização se concretize da forma mais natural possível.

\section{Considerações Finais}

Por tudo o que foi falado, concluísse a grande relevância do estudo sobre o real significado da ressocialização, sobre os desafios encontrados por mulheres nesse processo de ressocialização, como os projetos podem vir a auxiliar e amparar mulheres que passaram pelo sistema carcerário, além da importância da atuação de psicólogos dentro desses projetos. 
O trabalho, dentro deste contexto, serve como uma ponte para a diminuição do preconceito existente na sociedade, porém é capaz de se observar o desafio enfrentado por essas mulheres quando se trata desta questão. Por não terem profissionalização e principalmente por carregarem consigo o estigma de serem ex-detentas, é possível fazer a verificação de que o principal fator desencadeante de desafios pode se tornar um ciclo vicioso, no qual a mulher não consegue trabalho por conta do preconceito e, não consegue tirar de si o estigma pelo fato da sociedade não dar oportunidades para que estas consigam sair da vida do crime.

Consequentemente, se faz refletir na importância dos projetos sociais, no qual têm sua relevância neste âmbito pelo fato de terem uma abordagem acolhedora, buscando dar suporte para seu público-alvo, tendo como finalidade a reinserção destes na sociedade de forma menos agressiva, sobretudo dando oportunidades de saírem da vida do crime e quebrarem o estigma de que não é real a ideia da ressocialização. Destaca-se ainda a importância deste ponto, pois é por meio destes projetos que essas mulheres recebem o apoio, assistência que necessitam, além de receberem oportunidades que talvez não pudessem encontrar de outra maneira, como os cursos disponibilizados e a maior facilidade de serem inseridas no mercado de trabalho, por exemplo.

Deste modo, pode-se levar em consideração que os projetos sociais andam lado a lado com psicólogos, com o objetivo da promoção de oportunidades para essas mulheres dentro desses projetos. Os psicólogos entram de forma direta através de aconselhamentos, promoção da saúde mental com psicoterapias e palestras para que essas egressas não desistam do projeto, bem como auxiliar os membros ou funcionários durante as atividades e ajudar no levantamento de temas importantes a serem tratados dentro dessas palestras. Além de tudo, este profissional atua com entrevistas individuais e grupais, tendo então, o conhecimento das principais dúvidas e interesses do público-alvo. Deve-se também levar em consideração a importância deste profissional, pois a sua função é voltada para a garantia dos direitos humanos priorizando a autonomia do sujeito, ou seja, dentro da ressocialização de ex-detentas, o psicólogo tem como papel fundamental atuar de forma que este individuo tenha e receba todos os seus direitos e assim, dessa forma, garantir a sua ressocialização sem sofrer qualquer dano devido à uma estigmação.

Portanto, esta investigação visa levantar reflexões sobre a luta pelos direitos dessas mulheres que são tão oprimidas perante a sociedade, para que estas, por serem hoje o que são e estarem privadas de benefícios sociais, pelo preconceito da maioria, não percam sua vida desta forma tão trágica, como é a invisibilidade social. Para além deste estudo, existem vários outros pontos a serem debatidos ou a serem aprofundados sobre o tema em si, como a importância dos projetos sociais com mulheres ainda em cárcere e como isso pode facilitar no processo de ressocialização quando essas mulheres se tornarem egressas, bem como no levantamento estatístico dos benefícios que os Projetos Sociais podem trazer para egressas e para a sociedade em si.

\section{Referências}

Amazonas (Resolução n ${ }^{\circ}$ 14, de 27 de maio de 2010). Dispõe sobre o Projeto Reeducar - Redução ao Cárcere no âmbito do Poder Judiciário do Amazonas e dá outras providências. https://www.tjam.jus.br/images/2019/Monitoramento_Carcerário/resoluÇAึ̃o_reeducar_no _14.pdf.

Bezerra, S., \& Tino, J. (2019). Projeto Reeducar Promove Ação de Cidadania para Reeducandos e Familiares. https://www.tjam.jus.br/index.php/menu/salade-imprensa/1616-projeto-reeducar-promove-acao-de-cidadania-para-reeducandos-e-familiares.

Boeira, Laura dos Santos; et al. (2020). Síntese de Evidências: Enfrentando O Estigma Contra Pessoas Egressas do Sistema Prisional e Suas Famílias. Instituto Veredas.

Brasil (1988) Constituição da República Federativa do Brasil. Senado Federal.

Brasil. (Lei n. 7.210, de 11 de julho de 1984). Institui a Lei de Execução Penal. 11 jul. 1984. http://www.planalto.gov.br/ccivil_03/leis/17210.htm.

Cambria, G. P. (2018). Ressocializar: Ressocialização de Mulheres Ex-Detentas. Trabalho de Conclusão de Curso (Bacharelado em Arquitetura e Urbanismo). Universidade Presbiteriana Mackenzie, São Paulo.

Conselho Federal de Psicologia \& Centro de Referência Técnica em Psicologia e Políticas Públicas. (2009). A Prática Profissional dos(as) Psicólogos(as) no Sistema Prisional. Brasília: CFP. http://www.crpsp.org.br/interjustica/pdfs/outros/a-pratica-profissional-dos-as-psicologos-as-no-sistema-prisional.pdf. 
Cruces, A. V. V. (2010). A situação das Prisões no Brasil e o Trabalho dos Psicólogos Nessas Instituições: Uma Análise a Partir de Entrevistas com Egressos e Reincidentes. Bol. Acad. Paulista de Psicologia, 78 (10), 136-154. http://pepsic.bvsalud.org/scielo.php?script=sci_arttext\&pid=S1415-711X2010000100010.

Dias, S. \& Oliveira, L. J. de. (2014). A Reinserção Social Através do Trabalho: Responsabilidade Empresarial no Resgate da Dignidade da Pessoa Humana. Revista Jurídica Cesumar - Mestrado, 14 (1), 143-169. https://periodicos.unicesumar.edu.br/index.php/revjuridica/article/view/3248/2294. http://dx.doi.org/10.5902/1984644433426.

Filho, S. M. de S., \& Lima, V. A. A. de. (2020). Horta Pedagógica: Uma Pesquisa-Participante De Formação De Docentes Em Educação Por Projetos. Educação - Revista do Centro de UFSM, 45 (1), 1-28. https://www.researchgate.net/publication/341445338_Horta_Pedagogica_uma_pesquisaparticipante_de_formacao_de_docentes_em_educacao_por_projetos.

Gerhardt, T. E., \& Silveira, D. T. (2010). Métodos de Pesquisa. Série Educação a Distância.

Godoy, A. S. (1995). Pesquisa Qualitativa: Tipos Fundamentais. Revista de Administração de Empresas, 35 (3), 20-29. https://www.scielo.br/j/rae/a/ZX4cTGrqYfVhr7LvVyDBgdb/?lang=pt\&format=pdf. Doi: 10.1590/S0034-75901995000300004.

Helpes, S. S. (2020). A Superexploração do Trabalho Antes, Durante e Depois da Prisão: Histórias de Vida de Mulheres Egressas do Sistema Penitenciário. Entropia, 4 (7), 102-125. http://www.entropia.slg.br/index.php/entropia/article/view/154/156.

Lacerda, D. (2018). Ministro da Justiça lança o projeto "Mulheres Livres" em Santa Catarina nesta sexta-feira. Governo de Santa Catarina. https://www.sc.gov.br/noticias/temas/justica-e-defesa-da-cidadania/ministro-da-justica-chega-ao-estado-para-lancar-projeto-mulheres-livres.

Lanfredi, L. G. Sant'Ana; Pimenta, V. M.; Horta, R. de L. e; Daufemback, V.; Souza, T. A. de \& Zampier, D. N. (Coord.). (2020). Política Nacional de Atenção às Pessoas Egressas do Sistema Prisional. Brasília, DF: Conselho Nacional de Justiça - Departamento Penitenciário.

Leandro, M.; et al. (2018). Retorno à Sociedade: Percepções e Experiências de Ex-Detentas. Revista de Psicologia da IMED, 10 (1), 125-139. https://seer.imed.edu.br/index.php/revistapsico/article/view/2499/1774. Doi: 10.18256/2175-5027.2018.v10i1.2499.

Lira, Kamilla. (2017). Projeto Mãos Livres promove oficina de luminárias em barbante e PVC. http://www.amazonas.am.gov.br/2017/10/projeto-maos-livrespromove-oficina-de-luminarias-em-barbante-e-pvc/.

Medeiros, Ângelo. (2021). Programa Mulheres Livres Quer Amenizar Vulnerabilidade Social de Detentas em SC. https://www.deap.sc.gov.br/index.php/noticias/945-programa-mulheres-livres-quer-amenizar-vulnerabilidade-social-de-detentas-em-sc.

Ministério da Justiça e Segurança Pública. (2019). Santa Catarina Será Segundo Estado a Implantar Programa Mulheres Livres. https://www.gov.br/mj/ptbr/assuntos/noticias/santa-catarina-sera-segundo-estado-a-implantar-programa-mulheres-livres.

Ministério de Justiça e Segurança Pública. (2017). Paraná escolhido para começar projeto Mulheres Livres. https://www.justica.gov.br/news/parana-escolhidopara-comecar-projeto-mulheres-livres.

Nascimento, Jamilly. (2020). Penitenciária Feminina de Manaus tem 75,47\% das Detentas Inseridas no Programa "Trabalhando a Liberdade". http://www.seap.am.gov.br/penitenciaria-feminina-de-manaus-tem-7547-das-detentas-inseridas-no-programa-trabalhando-a-liberdade/.

Nassar, Victor \& Vieira, Milton Luiz Horn. (2017). Análise da Participação dos Usuários nos Conteúdos de Sites Institucionais a Partir dos Níveis de Interatividade. Intercom - RBCC, 40 (1), 121-142. http://portcom.intercom.org.br/revistas/index.php/revistaintercom/article/view/2640. Doi: 10.1590/18095844201717

Niquito, Thais Waideman; Ely, Regis Augusto \& Ribeiro, Felipe Garcia. (2018). Avaliação de Impacto das Assistências Técnicas do Sistema S no Mercado de Trabalho. RBE, 72 (2), 196-216. https://bibliotecadigital.fgv.br/ojs/index.php/rbe/article/view/71034/71879.

Nogueira, Roberto Martínez. (1998). Los Proyectos Sociales: De La Certeza Omnipotente Al Comportamiento Estratégico. Santiago de Chile: Comisión Económica para América Latina y el Caribe.

Novo, Benigno Núñez. (2019). A Psicologia na Ressocialização Prisional. Direironet. https://www.direitonet.com.br/artigos/exibir/10377/A-psicologia-naressocializacao-prisional.

Novo, Benigno Núñez. (2019). Preconceito é Crime. JusBrasil. https://benignonovonovo.jusbrasil.com.br/artigos/734303735/preconceito-e-crime.

Oliveira, Márcia Vânia Pereira de \& Nunes, Érica Pollyana Oliveira. (2018). Os Desafios de (Re)Inserção Socioprofissional da Mulher Egressa do Sistema Penitenciário em Palmas-To. Revista Humanidades e Inovação, 5 (11), 254-267. https://revista.unitins.br/index.php/humanidadeseinovacao/article/view/828.

Pagotto, Aline. (2014). Coral Maria Marias se apresenta em evento de Contabilidade. https://sejus.es.gov.br/Notícia/coral-maria-marias-se-apresenta-em-eventode-contabilidade.

Pastore, José. (2011). Trabalho para ex-infratores. São Paulo: Saraiva.

Peres, Gisele Pereira \& Matos, Márcia de Alencar Araújo. (2009). Boas Práticas do Sistema Penitenciário Nacional. Brasília: Ministério da Justiça Departamento Penitenciário Nacional.

Petraglia, Alessandra. (2019). Projeto ajuda ex-detentas a construir um novo plano de vida. https://catracalivre.com.br/cidadania/projeto-ajuda-ex-detentas-aconstruir-um-novo-plano-de-vida/.

Ribeiro, Fernanda. (2017). A Reinserção Social da Ex-Presidiária no Mercado de Trabalho. Revice - Revista de Ciências do Estado, 2 (1), 357-379. https://periodicos.ufmg.br/index.php/revice/article/view/5030/3098. 
Research, Society and Development, v. 10, n. 15, e135101522789, 2021

(CC BY 4.0) | ISSN 2525-3409 | DOI: http://dx.doi.org/10.33448/rsd-v10i15.22789

Santos, Juliana Estevão dos; Barbosa, Milka Alves Correia; Lima, José Rodolfo Tenório \& Cassundé, Fernanda Roda. (2018). Egressos do Sistema Prisional e a Gestão de Pessoas nas Organizações Receptoras: Um Estudo Multicasos em Organizações Alagoanas. In V CBEO Congresso Brasileiro de Estudos Organizacionais (p. 1-24). Curitiba, PR.

Souza, Eloisio Moulin de; Costa, Alessandra de Sá Mello da \& Lopes, Beatriz Correia. (2019). Ressocialização, Trabalho e Resistência: Mulheres Encarceradas e a Produção do Sujeito Delinquente. Cad. EBAPE.BR, 17 (2), 362-374. https://bibliotecadigital.fgv.br/ojs/index.php/cadernosebape/article/view/71382/75147.

Stephanou, Luis; Müller, Lúcia Helena \& Carvalho, Isabel Cristina de Moura. (2003). Guia Para Elaboração de Projetos Sociais. São Leopoldo: Sinodal.

TJAM. (2019). Reeducar: História - COMPOSIÇÃO E RECURSOS. https://www.tjam.jus.br/index.php/sobre-monitoramento/origem-e-historia-reeducar.

TJAM. (2019). Reeducar: Parcerias. https://www.tjam.jus.br/index.php/sobre-monitoramento/origem-e-historia-reeducar?start=8.

Umanizzare. (2020). A Umanizzare. http://umanizzarebrasil.com.br/quem-somos/.

Umanizzare. (2020). Projeto Lisbela: Empreendedorismo e Autoestima. http://umanizzarebrasil.com.br/projeto-lisbela/.

Umanizzare. (2020). Projeto Plantando a Liberdade. http://umanizzarebrasil.com.br/projeto-plantando-liberdade/. 